\title{
Academic performance after neurosurgery residency training in Turkey: a national survey
}

\author{
Fatih Yakar, MD, ${ }^{1}$ Sahin Hanalioglu, MD, PhD, FEBNS, ${ }^{2}$ Balkan Sahin, MD, ${ }^{3}$ \\ Emrah Egemen, MD, FEBNS, ${ }^{1}$ Umit A. Dere, MD, ${ }^{1}$ Ilker Kiraz, MD, ${ }^{1}$ M. Erdal Coskun, MD, ${ }^{1}$ and \\ Gokmen Kahilogullari, MD, PhD4
}

\begin{abstract}
1Department of Neurosurgery, Pamukkale University School of Medicine, Denizli; ${ }^{2}$ Department of Neurosurgery, Health Sciences University Diskapi Yildirim Beyazit Training and Research Hospital, Ankara; ${ }^{3}$ Department of Neurosurgery, Şişli Hamidiye Etfal Training and Research Hospital, Istanbul; and ${ }^{4}$ Department of Neurosurgery, Ankara University School of Medicine, Ibni Sina Hospital, Ankara, Turkey
\end{abstract}

OBJECTIVE Neurosurgery training programs aim to train specialists. In addition, they are expected to equip the residents with necessary knowledge and skills for academic development. This study aims to gain insights into academic productivity after neurosurgeons graduated from residency training in Turkey.

METHODS An electronic survey was sent to all Turkish Neurosurgical Society members ( $n=1662$ neurosurgeons) between September and November 2019. The number of participants was 289 (17.4\%). Participants were divided into subgroups based on three main factors: training institution type (university hospital [UH] vs training and research hospital [TRH]), training institution annual case volume (low [< 1000 or inadequate cranial/spinal case numbers] vs high [> 1000 and adequate cranial/spinal case numbers]), and training program accreditation status (accredited vs nonaccredited).

RESULTS The majority of the participants (64.7\%) graduated from the UHs. Those trained at UHs (vs TRHs) and high(vs low-) volume centers had their dissertations more frequently published in Science Citation Index/Science Citation Index-Expanded journals, gave more oral presentations after residency, had higher h-indices, had higher rates of reviewership for academic journals, and had greater participation in projects with grant support. In addition, graduates of accredited programs reported more PhD degrees than those of nonaccredited programs.

CONCLUSIONS Neurosurgeons trained in higher-case-volume, accredited programs, mostly in the UHs, performed better in terms of scientific activities and productivity in Turkey. Strong research emphasis and supportive measures should be instituted to increase academic performance during and after residency training.

https://thejns.org/doi/abs/10.3171/2019.12.FOCUS19825

KEYWORDS specialist; academic performance; survey; training

$\mathrm{H}$ EALTH service provider organizations in Turkey are divided into three levels. University hospitals (UHs; state/private) and training and research hospitals (TRHs) are the tertiary-level training hospitals. Universities are autonomous institutions, whereas the Turkish Ministry of Health governs TRHs. Other state hospitals with lower capacities form primary and secondary level care institutions. Programs of UHs and TRHs provide residency training. Neurosurgery residency training takes 5 years in Turkey, including 7 months of rotations within other related specialties such as neurology, emergency medicine, and radiology. Today, there are more than 1500 neurosurgeons and 83 neurosurgery training programs in Turkey.

Neurosurgery departments aim to educate new specialists and provide quality healthcare to patients. It is also obvious that continuous development of the field requires scientific research in addition to education and practice. For these reasons, training programs have a high responsibility to society; hence, specialty training needs to be kept

ABBREVIATIONS EANS = European Association of Neurological Societies; $\mathrm{SCI}=$ Science Citation Index; SCIE = Science Citation Index-Expanded; TNS = Turkish Neurosurgical Society; TRH = training and research hospital; $\mathrm{UH}=$ university hospital.

SUBMITTED October 30, 2019. ACCEPTED December 18, 2019.

INCLUDE WHEN CITING DOI: 10.3171/2019.12.FOCUS19825. 
to a high standard to equip the residents with the necessary knowledge and skills, not only for providing quality care but also for academic development. ${ }^{14}$ This study aims to gain insights into academic productivity after neurosurgeons graduated from residency training in Turkey. To the best of our knowledge, this is the first national survey that has investigated the contribution of neurosurgical resident education to academic competency in Turkey.

\section{Methods \\ Online Survey}

An online electronic survey was designed, consisting of 35 questions (Table 1). This survey's link was sent to the personal emails of all Turkish Neurosurgical Society (TNS) members ( $\mathrm{n}=1662$ neurosurgeons), and the responses of those who agreed to participate were evaluated. Multiple responses were impossible for those who used the same internet IP address.

Two hundred eighty-nine specialist neurosurgeons (17.4\%) participated in the survey. The participants were informed about the confidentiality of their data. All data were collected in an online database and then imported into Microsoft Excel. The survey was in Turkish as the native language and applied to only specialists (those who had already graduated from residency). No residents were included in this study.

\section{Subgrouping of Questions and Participants}

Questions were categorized into three groups: 1) baseline characteristics (including personal and institutional details), 2) professional training and development, and 3) scientific activity and productivity. Category 2 (professional training and development) is beyond the scope of this article, and thus was not further evaluated in the Results section. Participants were divided into subgroups based on three main factors: 1) training institution type (UH vs TRH); 2) training institution annual case volume (low $[<1000$ or inadequate cranial/spinal case numbers] vs high [ $>1000$ and adequate cranial/spinal case numbers]; these numerical values were determined according to the study of Stienen et al. ${ }^{13}$ ); and 3) training program accreditation (accredited vs nonaccredited).

\section{Statistical Analysis}

Statistical analyses were performed using IBM SPSS (version 22.0, IBM Corp.). Chi-square and Fisher's exact tests were used for comparisons between groups for categorical nominal variables, whereas the Mann-Whitney U-test and Kruskal-Wallis test were used for ordinal variables in two- and multiple-group comparisons, respectively. Correlation analysis was performed using Spearman's correlation coefficient test. A p value $<0.05$ was considered statistically significant.

\section{Results}

\section{Baseline Characteristics}

Demographics

All baseline characteristics are summarized in Table 2 .
The majority of the participants were male (92.7\%). Participants over 45 years of age (37.4\%) were the most common, followed by the 35-39 age group (27\%). More than one-quarter of the respondents $(26.6 \%)$ were specialists for more than 16 years, whereas another $26 \%$ graduated from residency only $1-4$ years ago.

\section{Institutional}

Most of the participants $(64.7 \%)$ graduated from the UHs. Those who graduated from accredited institutions comprised $51.2 \%$ of the respondents. The average time allocated for theoretical education was 0-2 hours (63\%) every week. The annual case volume of training institutions was mostly $>1000$ cases (54\%).

\section{Current Work}

Most of the participants (40.8\%) currently work at TRHs or other public hospitals affiliated with the Ministry of Health, whereas $28 \%, 8.3 \%$, and $22.8 \%$ work at state UHs, private UHs, and other private hospitals, respectively. Correlation analyses revealed correlations between training institution type and accreditation status (i.e., UHs are more accredited; $\rho=0.280, p<0.001)$, training institution type and current institution type (i.e., UH graduates are more likely to work in UHs; $\rho=0.122, p=0.038$ ), and training institution accreditation status and annual case volume (i.e., accredited centers have high case volume; $\rho$ $=0.238, \mathrm{p}<0.001)$.

\section{Scientific Activities and Productivity}

Detailed analysis of the items related to scientific activity and productivity are presented in Tables 3 and 4 . The majority of the dissertations comprised experimental animal (46\%) or retrospective clinical (25.3\%) studies. Nearly half of the participants (47.1\%) had not yet published their dissertations, whereas $9 \%$ published them in national journals, $7.6 \%$ in international non-Science Citation Index (SCI)/Science Citation Index-Expanded (SCIE) journals, and $36.3 \%$ in SCI/SCIE journals. Forty-two percent reported involvement in collaborative or interdisciplinary research work with another clinic. Nearly one-third of the participants had not given oral presentations at scientific meetings either during or after their residency. Half of the participants reported that they did not have a Google Scholar or Web of Science account and did not know about their h-index at all. One-fifth of the participants had an hindex $\geq 6$. Forty-three percent reported being involved in the peer-review process of scientific articles at least once, whereas frequent reviewers (at least 1 article per month) comprised only $14.2 \%$. Eighteen percent reported that they served on the editorial board of a national or international journal. Only $7.6 \%$ of the participants held a $\mathrm{PhD}$ degree, and only $10.5 \%$ owned a patent. The participation rate in a research project with grant support was 34.3\%.

Participants trained at UHs reported more experimental dissertations with a higher publication rate in SCI/ SCIE journals, oral presentations after graduation, higher h-indices, a higher rate of reviewer positions, and greater participation in projects with grant support.

Participants trained in high-volume centers reported 
TABLE 1. All questions from "Academic performance after neurosurgery residency training in Turkey: a national survey"

\begin{tabular}{|c|c|}
\hline Question & Possible Responses \\
\hline How old are you? (years) & $24-29,30-34,35-39,40-44,>45$ \\
\hline What is your gender? & Female, male \\
\hline How many years have you been a specialist neurosurgeon? & $1-4,5-8,9-12,13-16,>16$ \\
\hline What is the nature of your residency institution? & $\begin{array}{l}\text { State university, training and research hospital, private university, } \\
\text { foreign country }\end{array}$ \\
\hline Does your institution have national/international accreditation? & Yes, no \\
\hline $\begin{array}{l}\text { What was the time allocated for the theoretical education (lecture/journal clubs) in } \\
\text { your residency institution? }\end{array}$ & $0-2$ hours, $2-4$ hours, $4-6$ hours, $6-8$ hours, $>8$ hours \\
\hline What was the number of spinal cases per year in your institution? & $<400,>400$ \\
\hline What was the number of cranial cases per year in your institution? & $<600,>600$ \\
\hline $\begin{array}{l}\text { Did you have a case log of the tasks you took in the cases you participated in } \\
\text { your residency institution? }\end{array}$ & Yes, no \\
\hline
\end{tabular}
your residency institution?

Did you make an oral presentation at national/international congresses during 4 and more, 3, 2, 1, anytime your residency? How many times?

Did you make an oral presentation at national/international congress during your 4 and more, 3, 2, 1, anytime expertise after graduation from residency? How many times?

Did you visit another clinic in Turkey or a foreign country during or after your $\quad$ No; yes/in Turkey/at least once as an observer or fellow; yes/in a residency, how often, and in what capacity?

Have you received a scholarship from any national/international foundation during your time at another clinic? If not, why?

Are you a reviewer for national or international journals, and how often? foreign country as an observer or fellow

Yes/national; yes/international; no/l set my budget/l knew about the scholarships and I applied; no/l didn't know about scholarships

No; yes/once a month and more often; yes/every 3 months; yes/ every 6 months; yes/once a year or less

\begin{tabular}{ll}
\hline Are you an editor for a national or international journal? & Yes, no \\
\hline Do you have an animal test certificate? & Yes, no
\end{tabular}

How many times have you participated in cadaver courses at home/abroad during 4 and more, 3, 2, 1, anytime your residency?

Have you participated in any national/international cadaver courses after resi- $\quad 4$ and more, 3, 2, 1, anytime dency? How many times?

What is the nature of the institution you are currently working with?

What is your total weekly working hours?

Have you taken the national board exams?

State university, private university, training and research hospital/ state hospital, private hospital

Yes, no

Have you taken the international board (EANS, etc.) exams? Yes, no

Do you have a Google Scholar/Web of Science account, and what is your h-index No; yes/1-2; yes/3-4; yes/5-6; yes/>6 on these platforms?

Which of the following classifications does your specialty dissertation fit?

Anatomical study, retrospective case analysis, prospective case analysis, animal/experimental, other

Has your thesis been published?

Not yet; published/in a Turkish journal; published/an international index journal/not SCl or SCIE; published/SCI or SCIE

Did you collaborate/publish with a different clinic during your residency or exper- Yes, no tise?

How much time do you spend weekly reading neurosurgery-related texts?

Do you have national/international memberships in the sub-boards of one or more neurosurgical sub-branches (vascular, oncology, pediatrics, spine, endovascular)? Do you attend regular meetings?

Have you participated in any national or international SRP?

1 hour, 2 hours, 3 hours, 4 hours, 5 or more hours

No; yes/l attend meetings but not regularly

No; yes/in an SRP within the university; yes/as a research coordinator of the EU framework program SRP; yes/joint researcher in the framework program of the EU SRP; yes/internationally supported SRP outside the EU

Do you have a PhD degree? Yes, no

CONTINUED ON PAGE 4 » 
TABLE 1. All questions from "Academic performance after neurosurgery residency training in Turkey: a national survey"

\begin{tabular}{|c|c|}
\hline Question & Possible Responses \\
\hline Do you have a patent? & Yes, no \\
\hline $\begin{array}{l}\text { Did your institution provide anatomy/embryology/oncology/animal laboratory? If } \\
\text { yes, how often would you use it? }\end{array}$ & $\begin{array}{l}\text { No; yes/anytime; yes/average } 2 \text { hours per week; yes/average } 2 \\
\text { hours per month; yes/average } 3 \text { hours or more per month }\end{array}$ \\
\hline $\begin{array}{l}\text { Did you have the opportunity to work on 3D models/synthetic models/simulation/ } \\
\text { VR during your residency or expertise? }\end{array}$ & Yes, no \\
\hline $\begin{array}{l}\text { Do you perform any surgical/interventional procedures you observe in the clinic } \\
\text { as an observer or fellow in your current institution? }\end{array}$ & Yes, no \\
\hline $\begin{array}{l}\text { Are there any procedures that you have certified and started to apply after your } \\
\text { residency? }\end{array}$ & Yes/l do not apply; yes/l apply; no \\
\hline
\end{tabular}

EU = European Union; SRP = Scientific Research Project; VR = virtual reality.

more dissertations published in SCI/SCIE journals, oral presentations during and after residency, higher h-indices, and a higher rate of reviewer positions, editorships, and participation in projects with grant support.

Participants trained in accredited programs reported more dissertations published in SCI/SCIE journals, and a higher likelihood of holding a $\mathrm{PhD}$ degree.

\section{Discussion}

There are many recommendations for the standardization of neurosurgical education in the US ${ }^{8}$ and Europe, ${ }^{15}$ but there is no universally accepted standard training program. The European Union of Medical Specialists is responsible for ensuring the quality and improvement of medical specialties in Europe. ${ }^{12}$ Even though the American Board of Neurological Surgery has established strict guidelines and there is better standardization than in Europe, a comprehensive and standard curriculum cannot be applied in the US. ${ }^{4}$ As a result, the structure and quality of training programs are different for every country and teaching center. ${ }^{10}$

In Turkey, there is a qualification committee named the Turkish Neurosurgical Society Proficiency Board. This board publishes papers for the standardization of resident training and gives accreditation certificates to training clinics. Presently, 3 UHs and 2 TRHs fulfilling the requirements set by the committee have been certified, ${ }^{3}$ and 3 UHs are accredited by the European Association of Neurological Societies (EANS). However, applying for accreditation is entirely at the discretion of the clinics, as is the case for board certification for individual neurosurgeons, ${ }^{3}$ and there is no obligation. Therefore, it is also impossible to talk about the standardization of neurosurgery training in Turkey.

Congresses offer the opportunity for oral/poster presentations to be criticized one last time before being submitted to peer-reviewed journals. ${ }^{5}$ When the presentations made in orthopedic surgery and neurosurgery meetings are taken into account, $10.5 \%-66 \%$ of the abstracts are published in scientific journals. ${ }^{9}$ The abstracts of the American Association of Neurological Surgeons/Congress of Neurological Surgeons Joint Section on Pediatric
Neurological Surgery (AANS/CNS Pediatric Section) and the International Society for Pediatric Neurosurgery annual meetings progressed to publication at rates of $60.6 \%$ and $40.6 \%$, respectively, between the years 2009 and $2011 .^{2}$ Eksi et al. ${ }^{5}$ determined that the acceptance rate of presented abstracts in the annual scientific meetings of the TNS between the years 2011 and 2014 by peer-reviewed journals was $10.5 \%(326 / 3105)$, and that this rate is low, but similar to other international congresses. The results of the survey showed that neurosurgeons who graduated from UHs and high-case-volume clinics presented a higher number of oral presentations. The number of oral presentations was also high for specialists for more than 9 years, and this was probably because of the long practice period. Nevertheless, there is no information about how many of these presentations were published as scientific articles.

Publication of studies in peer-reviewed journals helps individuals contribute to the literature and bring innovative approaches to the research community. In addition, it provides a collaborative environment for scientists to advance in their fields of work..$^{2}$ Altinors et al. ${ }^{1}$ evaluated the contribution of Turkish scientists to the high-impact journals (Journal of Neurosurgery and Acta Neurochirurgica). All issues up to December 2015 were reviewed individually. The Turkish contribution to these two journals was $1.94 \%$ (556 articles). The rate of the articles that were produced entirely in Turkey was $60.61 \%$, and Turkish scientists were coauthors in the remaining articles. The article does not mention the individual characteristics of Turkish authors.

Clinical work, teaching, research, and management are traditionally the four primary requirements of an ideal academic neurosurgeon description. In the new era, the characteristics of academic neurosurgeons will be collaboration, flexibility, and leadership. Grant/endowment funding and developing multidisciplinary clinical and research programs are the additional responsibilities of academicians. Academics of the future should not act with an independent will, and they should be specialists in cooperation and delegation, able to keep up with change, be competent in their field, and focus on teamwork rather than individuality. ${ }^{11}$ Participation in clinical and basic 
TABLE 2. Baseline characteristics of the study participants $(n=289)$

\begin{tabular}{|c|c|}
\hline Question & Value (\%) \\
\hline \multicolumn{2}{|l|}{ Age, yrs } \\
\hline $24-29$ & $1(0.3)$ \\
\hline $30-34$ & $39(14)$ \\
\hline $35-39$ & $78(27)$ \\
\hline $40-44$ & $63(22)$ \\
\hline$>45$ & $108(37)$ \\
\hline \multicolumn{2}{|l|}{ Sex } \\
\hline Female & $21(7)$ \\
\hline Male & $268(93)$ \\
\hline \multicolumn{2}{|l|}{ How many years have you been a specialist neurosurgeon? } \\
\hline $1-4$ & $75(26)$ \\
\hline $5-8$ & $55(19)$ \\
\hline $9-12$ & $49(17)$ \\
\hline $13-16$ & $33(11)$ \\
\hline$>16$ & $77(27)$ \\
\hline \multicolumn{2}{|l|}{ What is the nature of your residency institution? } \\
\hline State university & $187(65)$ \\
\hline Education \& research hospital & $100(35)$ \\
\hline Private university & $2(0.7)$ \\
\hline Foreign country & $0(0)$ \\
\hline \multicolumn{2}{|l|}{ Does your institution have national/international accreditation? } \\
\hline Yes & $148(51)$ \\
\hline No & $141(49)$ \\
\hline \multicolumn{2}{|c|}{ What was the number of spinal cases per year in your institution? } \\
\hline$<400$ & $57(20)$ \\
\hline$>400$ & $232(80)$ \\
\hline \multicolumn{2}{|c|}{ What was the number of cranial cases per year in your institution? } \\
\hline$<600$ & $114(39)$ \\
\hline$>600$ & $175(61)$ \\
\hline \multicolumn{2}{|c|}{ Did you have a case log of the tasks you took in the cases you participated in your residency institution? } \\
\hline Yes & $154(53)$ \\
\hline No & $135(47)$ \\
\hline \multicolumn{2}{|c|}{ What is the nature of the institution you are currently working with? } \\
\hline State university & $81(28)$ \\
\hline Private university & $24(8)$ \\
\hline Education \& research hospital/state hospital & $118(41)$ \\
\hline Private hospital & $66(23)$ \\
\hline \multicolumn{2}{|l|}{ What is your total weekly working hours? } \\
\hline 40 & $79(27)$ \\
\hline 48 & $53(18)$ \\
\hline $49-60$ & $67(23)$ \\
\hline$>60$ & $90(31)$ \\
\hline
\end{tabular}

research during residency is a vital process in acquiring basic scientific concepts. Creating a scientific interest will open the way for being an academic researcher. Moreover, it will give the surgeon the chance to be a part of science and give the ability to direct future treatment modalities. ${ }^{4}$ The $\mathrm{h}$-index is a standard indicator to determine the ranking of academic activity. ${ }^{6}$ Graduates of UHs and high-case-volume clinics reported higher h-indices in our survey. Collaborative/interdisciplinary research and study with grant support was more frequent in graduates of UHs and high-case-volume clinics.

\section{Limitations}

There are several limitations to this study. There are 

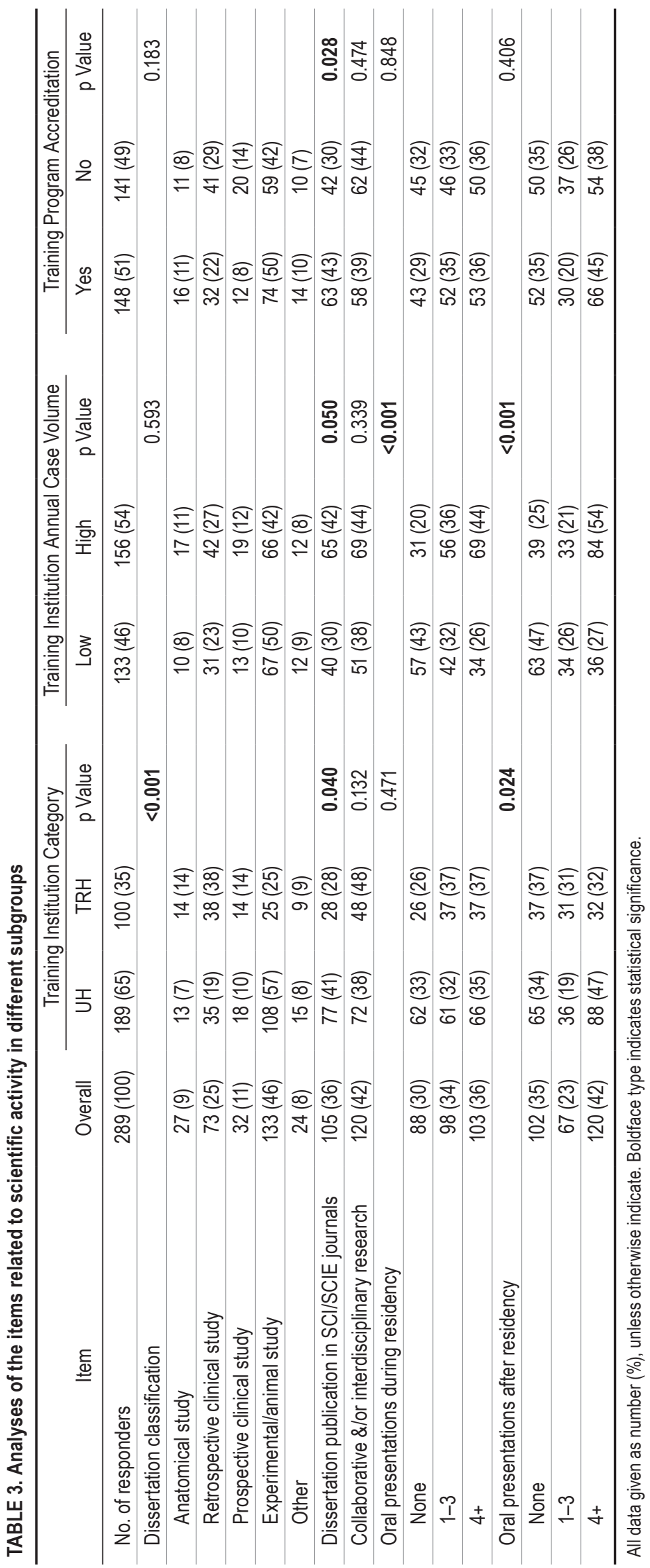


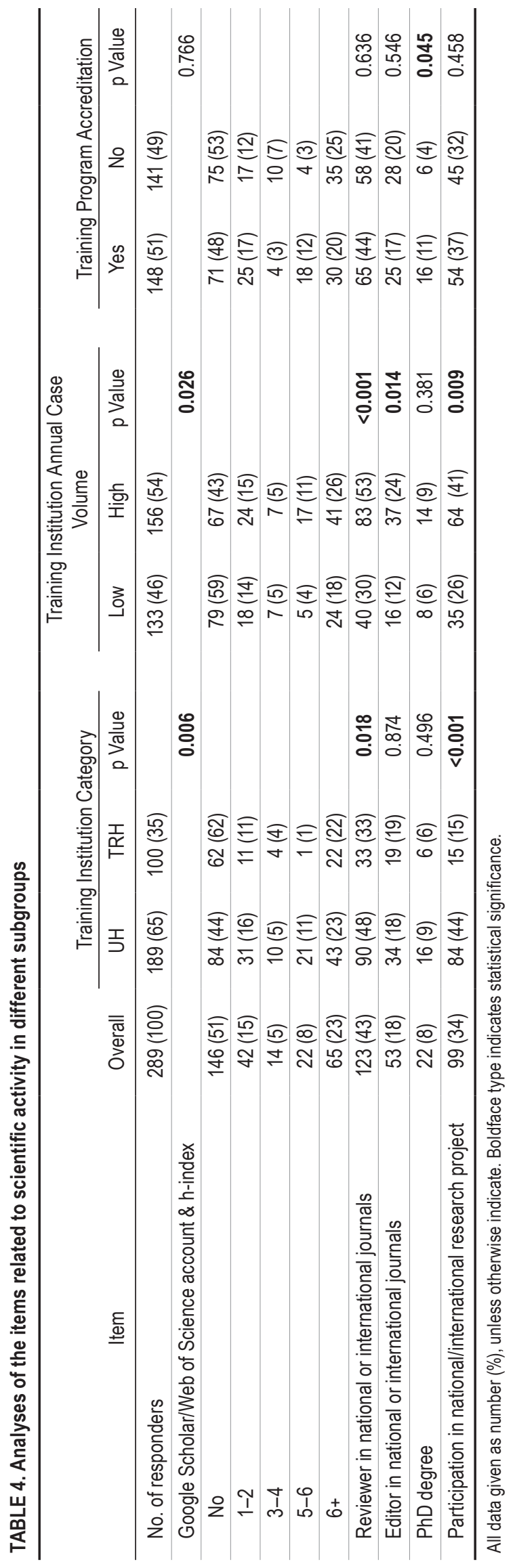

more than 1500 neurosurgeons in Turkey and the sample for this study is less than 20\%. This sample will not accurately reflect the actual data but will be informative. It could also be said that the participants who did not participate in the survey did not have any concerns about academic competency. As a result, it can be said that the sample was applied to a group that takes academic competency seriously, which is a limitation. Finally, a large number of statistical comparisons can be made with the data obtained from the 35 questions asked to the participants. However, in this study, we primarily wanted to measure the differences in clinics that train specialists and the personal awareness of neurosurgeons.

\section{Conclusions}

The main aim of neurosurgical residency education is to teach clinical knowledge and surgical skills, but also to teach the principles of the scientific method. Neurosurgeons trained in high-volume accredited programs, mostly in UHs, performed better in terms of scientific activities and productivity in Turkey. Thus, we advocate for institutional accreditation, participation in board examinations, and more emphasis on scientific research during and after residency training.

\section{References}

1. Altinors N, Comert S, Sonmez E, Altinel F: Turkish contribution to Journal of Neurosurgery and Acta Neurochirurgica. Turk Neurosurg 27:1007-1015, 2017

2. Bonfield CM, Pellegrino R, Berkman J, Naftel RP, Shannon $\mathrm{CN}$, Wellons JC: Oral presentation to publication: publication rates of abstract presentations across two pediatric neurosurgical meetings. J Neurosurg Pediatr 21:650-654, 2018

3. Bulduk EB, Yilmaz C: Turkish Board of Neurological Surgery. Turk Neurosurg 29:121-126, 2019

4. Burkhardt JK, Zinn PO, Bozinov O, Colen RR, Bertalanffy $\mathrm{H}$, Kasper EM: Neurosurgical education in Europe and the United States of America. Neurosurg Rev 33:409-417, 2010

5. Eksi MS, Kaplan SC, Yilmaz B, Akakin A, Toktas ZO, Konya D, et al: Publication rates of presentations at annual scientific meetings of the Turkish Neurosurgical Society. Turk Neurosurg 27:142-145, 2017

6. Jamjoom AA, Wiggins AN, Loan JJ, Emelifeoneu J, Fouyas IP, Brennan PM: Academic productivity of neurosurgeons working in the United Kingdom: insights from the h-index and its variants. World Neurosurg 86:287-293, 2016

7. Kiris T, Akçakaya MO: History and current status of neurosurgery in Turkey. Neurosurgery 63 (Suppl 1):56-63, 2016

8. Martin M, Burn SC: Neurosurgical residency in the United States: a trainee's experience. Acta Neurochir (Wien) 147:1211-1212, 2005

9. Ramos MB, Falavigna A, Abduljabbar F, Rabau O, Ferland $\mathrm{CE}$, Weber $\mathrm{MH}$, et al: Assessing publication rate of abstracts presented in spine conferences as a quality benchmark: the example of the Canadian Spine Society Annual Meetings. World Neurosurg 131:e339-e345, 2019

10. Sauvageau E, Hopkins LN: Training in cerebrovascular disease: do we need to change the way we train residents? Neurosurgery 59 (5 Suppl 3):S282-S286, S3-S13, 2006

11. Squitieri L, Chung KC: Funding research in the twenty-first century: current opinions and future directions. Hand Clin 30:367-376, vii, 2014

12. Steers J, Reulen HJ, Lindsay KW; European Union of Medical Specialists; Joint Residency Advisory and Accreditation 
Committee: UEMS charter on training of medical specialists in the EU-the new neurosurgical training charter. Acta Neurochir Suppl (Wien) 90:3-11, 2004

13. Stienen MN, Gempt J, Gautschi OP, Demetriades AK, Netuka D, Kuhlen DE, et al: Neurosurgical resident training in Germany. J Neurol Surg A Cent Eur Neurosurg 78:337-343, 2017

14. Stienen MN, Netuka D, Demetriades AK, Ringel F, Gautschi OP, Gempt J, et al: Neurosurgical resident education in Europe-results of a multinational survey. Acta Neurochir (Wien) 158:3-15, 2016

15. Trojanowski T: Report of the JRAAC on the situation of the accreditation training programmes in Europe. Acta Neurochir (Wien) 150:851-853, 2008

\section{Disclosures}

The authors report no conflict of interest concerning the materials or methods used in this study or the findings specified in this paper.

\section{Author Contributions}

Conception and design: Yakar. Acquisition of data: Yakar, Hanalioglu, Dere, Kiraz, Coskun. Analysis and interpretation of data: Hanalioglu, Sahin. Drafting the article: Yakar, Hanalioglu, Sahin, Egemen. Critically revising the article: Hanalioglu, Egemen, Kahilogullari. Reviewed submitted version of manuscript: all authors. Approved the final version of the manuscript on behalf of all authors: Yakar. Statistical analysis: Hanalioglu, Sahin. Study supervision: Yakar, Kahilogullari.

\section{Correspondence}

Fatih Yakar: Pamukkale University School of Medicine, Denizli, Turkey.yakarneurosurgery@gmail.com. 